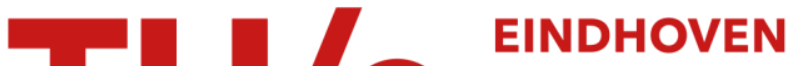 UNIVERSITY OF TECHNOLOGY
}

\section{Cutting forces and their influences upon the surface integrity in single-point diamond turning}

\section{Citation for published version (APA):}

Lo-A-Foe, T. C. G., Dautzenberg, J. H., \& van der Wolf, A. C. H. (1988). Cutting forces and their influences upon the surface integrity in single-point diamond turning. In Ultraprecision in manufacturing engineering:

proceedings of the international congress for ultraprecision technology, May 1988, Aachen, FRG / Ed. M. Weck, R. Hartel (pp. 110-125). Springer.

Document status and date:

Published: 01/01/1988

\section{Document Version:}

Publisher's PDF, also known as Version of Record (includes final page, issue and volume numbers)

\section{Please check the document version of this publication:}

- A submitted manuscript is the version of the article upon submission and before peer-review. There can be important differences between the submitted version and the official published version of record. People interested in the research are advised to contact the author for the final version of the publication, or visit the $\mathrm{DOI}$ to the publisher's website.

- The final author version and the galley proof are versions of the publication after peer review.

- The final published version features the final layout of the paper including the volume, issue and page numbers.

Link to publication

\section{General rights}

Copyright and moral rights for the publications made accessible in the public portal are retained by the authors and/or other copyright owners and it is a condition of accessing publications that users recognise and abide by the legal requirements associated with these rights.

- Users may download and print one copy of any publication from the public portal for the purpose of private study or research.

- You may not further distribute the material or use it for any profit-making activity or commercial gain

- You may freely distribute the URL identifying the publication in the public portal.

If the publication is distributed under the terms of Article 25fa of the Dutch Copyright Act, indicated by the "Taverne" license above, please follow below link for the End User Agreement:

www.tue.nl/taverne

Take down policy

If you believe that this document breaches copyright please contact us at:

openaccess@tue.nl

providing details and we will investigate your claim. 


\title{
Cutting Forces and Their Influences Upon the Surface Integrity in Single-Point Diamond Turning
}

\author{
T.C.G. Lo-A-Foe, J.H. Dautzenberg and A.C.H. van der Wolf \\ Department of Production Engineering and Automation. \\ Faculty of Mechanical Engineering, \\ Eindhoven University of Technology. \\ The Netherlands.
}

\section{Summary}

A model has been developed for determining the cutting forces.

The experiments, which have been carried out in order to evaluate the model, illustrate the tendency of a satisfying correspondence between the theory and the experimental results, especially when taking into account the forces on the clearance face. The force relationships are implemented in a numerical model for estimating the surface roughness. With the aid of this model the surface profiles of diamond-turned workpieces can be estimated within $10 \%$ and an examination of the cutting forces upon the surface roughness can be made.

\section{Introduction}

Single-point diamond cutting is a cutting process in which a diamond tool on a precision lathe is used for making products with a high surface quality. The tolerances of these products are $0.2 \mu \mathrm{m}$ for the roundness, $0.1 \mu \mathrm{m}$ per $100 \mathrm{~mm}$ for the straightness and 0.01 to $0.1 \mathrm{\mu m}$ for the roughness $\left(R_{z}\right)$.

These accuracies are very high, but they can be achieved nowadays.

The problem is that the understanding of the cutting process is still insufficient in order to determine the optimal cutting conditions as well as to develop a simple machine tool monitoring system in mass production.

Most of the input parameters. which are the properties of the workmaterial, the geometry and material properties of the tool, the properties of the cutting fluid and the static, dynamic and thermal behaviour of the machine. play an important role in single-point diamond turning.

During the process these parameters interact with the strains, the cutting forces and the temperatures, so a lot of these will have both direct and indirect influences upon the surface quality.

The aim of this study is to quantify the influences of the input parameters upon the cutting forces and the forces upon the surface integrity.

In the past several cutting models have been introduced. 
The first important model was made by Merchant [1], who was followed by several others like Lee and Shaffer [2] and Palmer and Oxley [3].

All these model have a restricted validity and several explanations have been given for the divergency. Features that have been ignored in the models are the influence of the hydrostatic pressure upon the shear flow stress [4], the forces on the clearance face [5], the nose forces [6], the side spread of the chip [7], the strain rate and the temperature upon the material properties [8], the chip curl [9] and the stress distributions on the rake face [10]. Although the incorporation of these factors results in some improvement of the models, none of them have been generally accepted yet, mainly due to the uncertainties and complexities associated with the accurate measurement of the parameters involved.

In this study a model introduced by Dautzenberg [11] is chosen because of the promising experimental correspondence and the fact that it leaves room for the incorporation of several features.

The force relationships will be implemented in a numerical model for estimating the surface roughness and this model will be evaluated for operating conditions in single-point diamond cutting.

\section{The model}

2.1. The forces on the rake face.

The model is based on the following assumptions (Fig.1):

- cutting is a two-dimensional plastic process.

- there are two regions of deformation.

In the first region the chip flow is changed without any thickening of the chip and in region 2 the chip thickness increases due to the friction between the chip and the tool.

- the supplied power is completely dissipated by the two plastic processes.

- the process is continuous.

- the workmaterial behaves according to the constitutive equation:

$$
\begin{aligned}
\bar{\sigma}=\mathrm{C}^{-\mathrm{n}} & \\
\text { where }: \bar{\sigma} & =\text { effective stress } \\
\bar{\epsilon} & =\text { effective strain } \\
n & =\text { strain hardening exponent } \\
\mathrm{C} & =\text { specific stress }
\end{aligned}
$$


For the global equilibrium of the tool, it holds that:

$$
\begin{aligned}
F_{w}=F_{v} \cdot \sin \gamma+F_{f} \cdot \cos \gamma \\
F_{n}=F_{v} \cdot \cos \gamma+F_{f} \cdot \sin \gamma \\
\text { where: } F_{w}=\text { friction force } \\
F_{v}=\text { cutting force } \\
F_{f}=\text { feed force } \\
F_{n}=\text { normal force } \\
\gamma=\text { rake angle }
\end{aligned}
$$

In region 1 (Fig.1B) the chip velocity is the same as the cutting speed. Area 1 is unloaded and on the areas 2 and 3 forces and a moment are in effect.

The power balance is:

$$
F_{v} \cdot v-F_{w} \cdot v=\int_{0}^{\bar{\epsilon}} \sigma \cdot d \epsilon \cdot A \cdot v
$$

Substitution of Eq.(1) in Eq. (4) and dividing by the term C.A.v gives:

$$
\begin{aligned}
F_{\mathrm{V}}^{*}=F_{\mathrm{W}}^{*}+\int_{0}^{\epsilon_{1}} \bar{\epsilon}^{-n} \cdot d \bar{\epsilon} \\
\text { with: } F_{\mathrm{v}}^{*}=\frac{F_{v}}{C A}=\text { cutting force number (dimensionless) } \\
F_{\mathrm{w}}^{*}=\frac{F_{\mathrm{w}}}{C A}=\text { friction force number (dimensionless) } \\
\bar{\epsilon}_{1}=\text { effective enddeformation in region } 1
\end{aligned}
$$

Eq. (5) holds for each plastic process in region 1 i.e. bending or shear.

The integral $\int_{0}^{\epsilon} 1 \bar{\epsilon}^{n} \cdot d \bar{\epsilon}$ depends upon the number of shear planes, $m$, in region 1, which may vary between 1 and $\infty$.

- For one shear plane $(m=1)$ the relationship between the forces is:

$$
F_{v}^{*}=F_{W}^{*}+\frac{1}{n+1} \cdot\left\{\frac{2}{\sqrt{3}} \cdot \tan \left(\frac{\pi-2 \gamma}{4}\right)\right\}^{n+1}
$$

- For $m=\infty$ :

$$
F_{v}^{*}=F_{W}^{*}+\frac{1}{n+1} \cdot\left\{\frac{\pi-2 \gamma}{2 \sqrt{3}}\right\}^{n+1}
$$


The differences between these relationships and those of Merchant and Lee and Shaffer are shown in the Fig.2. The relationships derived from the models of Merchant and 'Lee and Shaffer are:

$$
\begin{aligned}
& F_{V}=\tau \cdot A \cdot \frac{\cos (\beta-\gamma)}{\cos (\varphi+\beta-\gamma) \cdot \sin \varphi} \\
& F_{W}=\tau \cdot A \cdot \frac{\sin \beta}{\cos (\varphi+\beta-\gamma) \cdot \sin \varphi}
\end{aligned}
$$

where:

$A=$ the area of the undeformed chip section

$$
\begin{aligned}
\varphi=\text { the shear angle } & =45^{\circ}-\frac{\beta}{2}+\frac{\gamma}{2} \text { for Merchant } \\
& =45^{\circ}-\beta+\gamma \text { for Lee and Shaffer }
\end{aligned}
$$

$\beta=$ the friction angle between the tool and the chip material

$$
T=\text { the shear stress }=\frac{1}{\sqrt{3}} \cdot C \cdot \epsilon^{-n}=\frac{1}{\sqrt{3}} \cdot C \cdot\left(\frac{\cos \gamma}{\sqrt{3} \cdot \sin \varphi \cdot \cos (\varphi-\gamma)}\right)^{n}
$$

The differences can be imputed to the following reasons:

- In applying the minimum energy principe Merchant assumed that, contrary to Eq.14, the shear stress on the shear plane is independent of the shear angle.

- The model of Lee and Shaffer is a slipline field solution with the assumptions that the material cut behaves as an ideal plastic which does not strain harden and that there is one shear plane which represents a direction of maximum shear stress. This gives the same relationship as the model of Dautzenberg for one shear plane $(m=1)$ and no strain hardening $(n=0)$, but for other values the relationships will be different.

Because single-point diamond cutting is a three-dimensional non-orthogonal process, in which the chip can be regarded as the sum of oblique chips having various thicknesses (Fig.3), the equations cannot be used wi thout modifications.

For the sake of simplicity the following assumptions are made:

- the cutting process is a two-dimensional process with a cutting edge $k$, which is the same as the chip flow angle.

- the direction of the chip flow is perpendicular to the tool edge in the middle of the width of contact between the tool edge and the workmaterial. 
With these assumptions only the Eqs. (2) and (3) change:

$$
\begin{aligned}
& F_{\mathrm{w}}=F_{\mathrm{v}} \cdot \sin \gamma+\left(F_{f} \cdot \sin \kappa+F_{p} \cdot \cos \kappa\right) \cos \gamma \\
& F_{n}=F_{v} \cdot \cos \gamma+\left(F_{f} \cdot \sin \kappa+F_{p} \cdot \cos \kappa\right) \sin \gamma
\end{aligned}
$$

When comparing the theoretical results with the experimental data [12] a moderate agreement is obtained (Fig.4). The deviations are mainly due to tool wear and will be explained in the following paragraph.

\subsection{The forces on the clearance face}

The previous model is based on the assumption that the total supplied energy is consumed in the primary and secondary shear zone only.

If the tool edge is infinitely sharp the forces on the clearance face and thus the energy dissipated in the burnishing process will be small.

However, tool edges in practice are not perfectly sharp and even if they are, a rapid breakdown will cause a certain dullness of the edge.

A rapid increase of the forces during cutting, especially for aluminium, is to be seen in Fig.5. This increase is mainly due to flank wear.

If the cutting time for one tool is longer than 25 minutes, as was the case in the experiments for evaluating the cutting model, the influence of the forces on the clearance face will be considerable.

In order to correct for the tool wear, the experiments have been carried out in a sequence of continually increasing contact width $\mathrm{b}_{\mathrm{ce}}$. The increase of the forces due to tool wear of one measuring cycle is approximated by the difference between the forces measured in the last and in the first section of the testpiece. The correction for each measuring cycle is the sum of extra forces of the preceding measuring cycles.

If the measured forces are corrected for the forces on the clearance face the experimental data can be fitted very well to a line which is parallel to the theoretical lines (Fig.6) and using C-values which are more than double factor 2.3 for brass and factor 2.4 for aluminium - the values obtained from tensile tests, results in an excellent agreement between the theory and the experimental data (Fig.7).

A rough approximation of the forces on the clearance face due to flank wear can be made with a simple model which is based on the following assumptions:

1. The flank wear land is parallel to the cutting direction and

2. The normal stresses on the clearance face are uniform and equal to the the effective flow stress in region 1 of the cutting model. 
With these assumptions the forces on the clearance face will be:

$$
\begin{aligned}
& \Delta \mathrm{F}_{\mathrm{W}}=\mathrm{A}_{\mathrm{VB}} \cdot \sigma \\
& \Delta \mathrm{F}_{\mathrm{v}}=\mu_{\mathrm{f}} \cdot \mathrm{A}_{\mathrm{VB}} \cdot \sigma \\
& \text { where } \sigma=\text { the flow stress } \\
& A_{V B}=\text { the area of contact between workpiece and the } f \text { lank wear } \\
& \text { land } \\
& \mu_{f}=\text { the coefficient of friction between the tool and the } \\
& \text { workpiece at the flank face. }
\end{aligned}
$$

\subsection{The force relationships}

A good approximation of the forces on the rake face can be made with the simple relationship:

$$
F_{v}^{*}=F_{w}^{*}+1
$$

However, this is not sufficient for predicting the cutting forces, because there are two unknown variables and only one equation is available. A second equation is:

$$
\mathrm{F}_{\mathrm{W}}^{*}=\mu_{\mathrm{r}} \cdot \mathrm{F}_{\mathrm{v}}^{*}
$$

where $\mu_{r}=$ the mean coefficient of friction between the tool and the workpiece on the rake face.

Fig. 6 shows that the mean friction coefficient is not constant, but a lot of the experimental data can be described with a constant friction coefficient, especially when brass is used as work-piece material.

Combination of Eq. (19) and Eq.(20) yields:

$$
\begin{aligned}
& F_{v}^{*}=\frac{1}{1-\mu_{r}} \\
& F_{W}^{*}=\frac{\mu}{1-\mu_{r}}
\end{aligned}
$$

The forces on the clearance face can be estimated with the equations:

$$
\begin{aligned}
& \Delta \mathrm{F}_{\mathrm{w}}=A_{\mathrm{VB}} \cdot \sigma \\
& \Delta \mathrm{F}_{\mathrm{v}}=\mu_{\mathrm{f}} \cdot A_{\mathrm{VB}} \cdot \sigma
\end{aligned}
$$

These relationships are implemented in a numerical model [12] for estimating the surface profiles. This model will be discussed in the following pages. 


\subsection{The roughness model}

An iterative process [13] is used for determining the displacements of the tool with respect to the work-piece which are caused by the operational setting of the machine, the dynamics of the machine and the cutting forces. The program starts with a calculation of the displacements of the tool with respect to the work-piece due to the operational setting of the machine and their variations caused by vibrations.

The geometry of the chip section (Fig.8), resulting from these displacements. the profile of the cutting edge and the surface profile of the work-piece before cutting, is used for calculating the cutting forces. These cutting forces and the stiffnesses between the work-piece and the tool determine the additional displacements, which will change the position of the tool with relation to the work-piece and hence the area of the undeformed chip section and consequently the cutting forces.

So the calculation of the cutting forces and subsequent displacements is repeated until the difference between two successive positions of the tool relative to the work-piece is less than $0.1 \mathrm{~nm}$.

The final position and the profile of the cutting edge are used for determining the surface profile.

The determination of the whole profile is followed by a calculation of the roughness parameters $\left(R_{a}, R_{q}, R_{t}\right)$.

\section{Experiments}

Turning tests with aluminium and brass were carried out on a lathe with hydrostatic bearings in order to evaluate the model.

The dynamic behaviour of the lathe was determined from modal analysis using a HP 5423 A Fourier Analyzer.

The cutting forces were measured with a dynamometer having a three component Kistler-piezo-element with a resolution of a few $\mathrm{mN}$.

The surface roughness was measured with both stylus and optical (modified Compact Disc sensor [14]) techniques.

The optical sensor was used for measuring the tool geometry too.

The test conditions were:

- number of revolutions : $300-2400 \mathrm{r} / \mathrm{min}$

- feed velocity : $50-300 \mu \mathrm{m} / \mathrm{s}$

- depth of cut : $5-20 \mu \mathrm{m}$

- radius of the tool : 0.2 or $1.0 \mathrm{~mm}$ 


\section{Results and discussion}

A satisfactory agreement between experimental and theoretical results is illustrated in Figs.9. 10, and 11. The differences between the estimated and measured roughness values are less than $10 \%$ in most instances. The deviations could have been due to one or more of the following reasons : a The results of the vibration analysis were used for estimating the surface profile. Other fluctuations that could have occurred when machining the test-pieces, due to slipping of the belts were not taken into account. b Metallurgical properties of the work-piece material were not included in the model; therefore any roughness due to voids and impurities, as well as, anisotropy of the material behaviour were omitted from the calculations.

c The accuracy of the measuring equipment was restricted to a few $\mathrm{nm}$.

d Progress of the wear of the cutting edge during machining.

The influence of cutting forces upon surface roughness appeared to be quite small. Variation of these - by changing the depth of cut or using other materials (Fig.11) - does not affect the surface roughness remarkably. This is not surprising as the variation of the cutting forces is less than $50 \mathrm{mN}$ and the stiffness between the work-piece and the tool is about $10^{7} \mathrm{~N} / \mathrm{m}$, so the roughness due to variation of the forces is less than $5 \mathrm{~nm}$.

The differences in the surface profiles shown in Fig. 11 are due mainly to differences in the phase angles of the wave forms.

On the contrary the influence of the cutting forces on the shape accuracy can be large (magnitude of order $0.1 \mu \mathrm{m}$ ), especially when the tool wear or the depth of cut is large.

\section{Conclusions}

a. The cutting forces can be approximated with some simple relationships.

b. The surface profiles of diamond-turned work-pieces can be estimated within $10 \%$.

c. The influence of cutting forces upon the surface roughness is relative small but their influence upon the shape can be large.

\section{Acknowledgements}

These investigations were supported by the Netherlands Foundation for Technical Research (STW), future Technical Science Branch/ Division of the Nether lands Organization for the Advancement of Pure Research (ZWO). This support is gratefully acknowledged.

The authors are indebted to Mr. J.C. Manders . Mr. J.A.B. van Dijck and Mr. K.G. Struik for their expert assistance, and to Prof. ir. F. Doorschot and ir. T.G. Gijsbers for their support and suggestions. 


\section{References}

1. Merchant, M.E.: Mechanics of the metal-cutting process. Journal of the Applied Physics, 16, 1945,p.267-318.

2. Lee, E.H.; Shaffer, B.W.: The theory of plasticity applied to a problem of machining.

ASME Journal of Applied Mechanics,73, 1951,p.405-413.

3. Palmer, W.B.; Oxley, P.L.B.: Mechanics of or thogonal machining.

Proc. Inst. Mech. Engrs. . 173, 1959, p. 623-654.

4. Santhanam, S. ; Shaw, M.C.: Flow characteristic for the complex stress state in metal cutting.

Annals of the CIRP, 34,1985,p.109-111.

5. Spaans, C. : An exact method to determine the forces on the clearance face. Annals of the CIRP, 15, 1967,p.463-469.

6. Abdelmoneim, M.E.: Scrutton. R.F.: Tcol edge roundness and stable build-up formation in finish machining.

ASME Journal of Engineering for Industry,96B, 1974, p. 1258-1267.

7. Banerjee, s.K.: The limit of continuity in some single phase materials during machining and its correlation with torsion testing.

Development of Production Systems, Proc. $2^{\text {nd }}$ ICPR, 1974,p.89-110;

8. Fenton, R.G.; Oxley, P.L.B.: Mechanics of or thogonal machining allowing for the effect of strain rate and temperature on tool-chip friction. Proc. Inst. Mech. Engrs., 183(22), 1968-1969, p.417-438;

9. Dewhurst, P.: Is the machining process uniquely defined? Annals of the CIRP, 27/11,1978, p.1-4.

10. De Chiffre, L.; Wanheim, T.: What can we do about chip formation mechanics?

Annals of the CIRP, 34,1985,p.129-132.

11. Dautzenberg, J.H.; Vosmer, J.: Cutting force relations for an arbitrary deformation model.

Proc. $2^{\text {nd }}$ Conf. Irish Manufacturing Committee (Ireland), 1985.p.207-218.

12. Lo-A-Foe, T.C.G.: Dautzenberg, J.H.; van der Wolf, A.C.H.: A model for the micro-cutting forces o: imp-ferrous metals.

Proc. $5^{\text {th }}$ Polytechnics Symp. on Manufacturing Engineering (England). 1986,p.346-362.

13. Lo-A-Foe, T.C.G.; Dautzenberg, J.H.; Struik, K.G.; van der Wolf, A.C.H.: Cutting parameters and surface roughness in single-point diamond cutting. Proc. VII. Int. Oberf lachenkol loquium Kar 1-Marx-Stadt, 1988, p. 188-195.

14. Struik, K.G.; Fan Muchang : Measurement of shape and roughness by a modified Compact Disc sensor coupled to a computer.

Abstracts $4^{\text {th }}$ Int. Precision Engineering Seminar (England), 1987,p.81-90. 

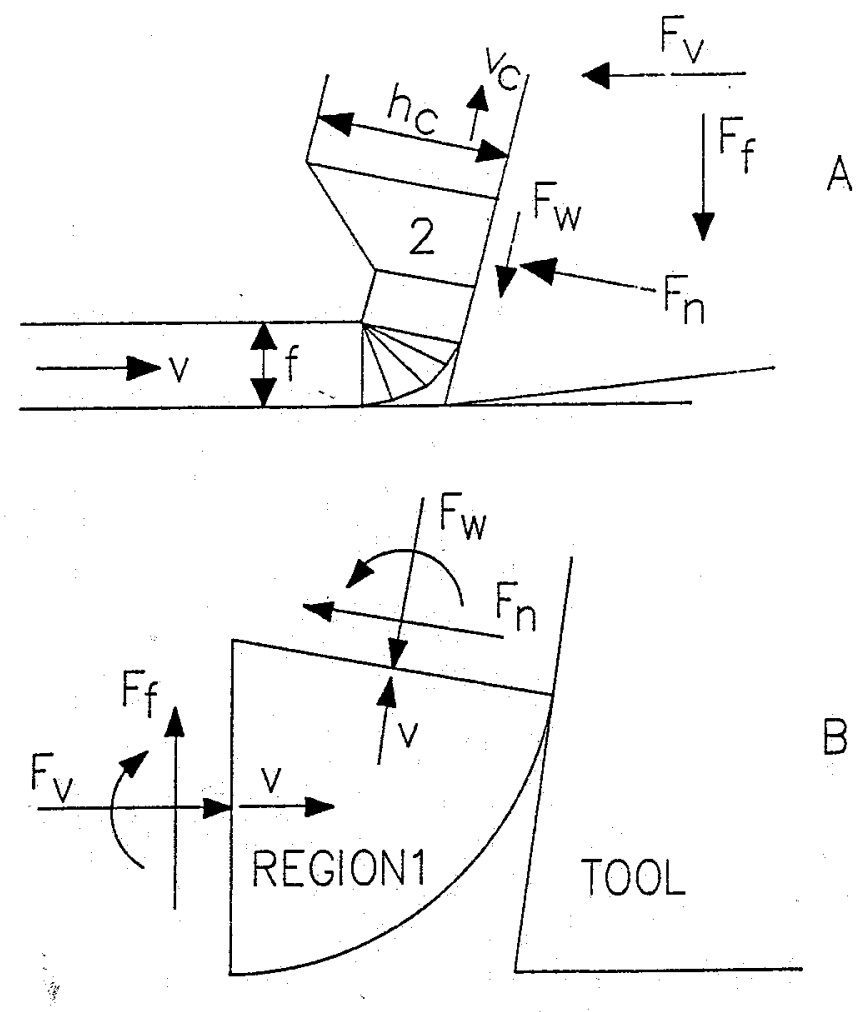

Fig.1. Representation of the two dimensional cutting process 

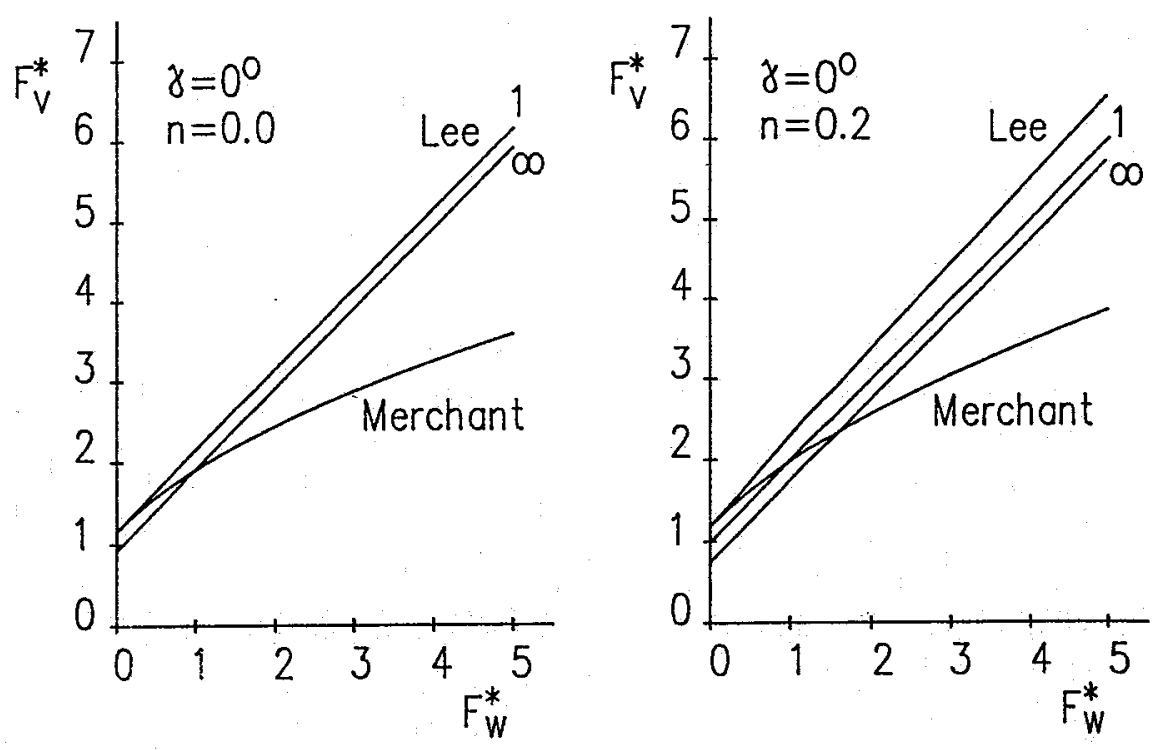

Fig.2. The cutting force number versus the friction force number for several models

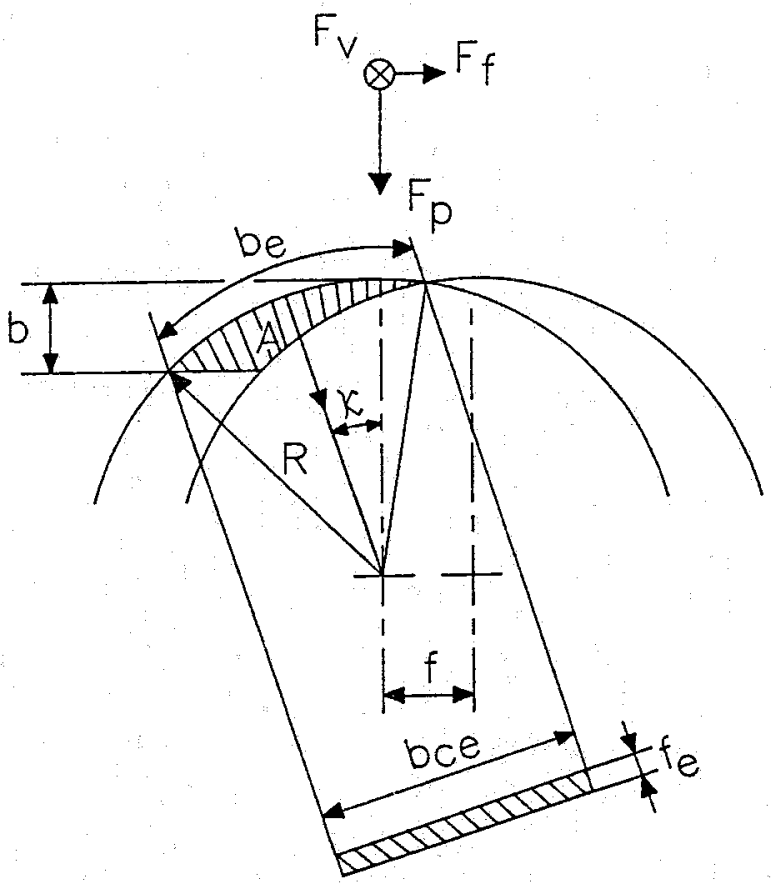

Fig.3. The geometry in single-point diamond cutting 

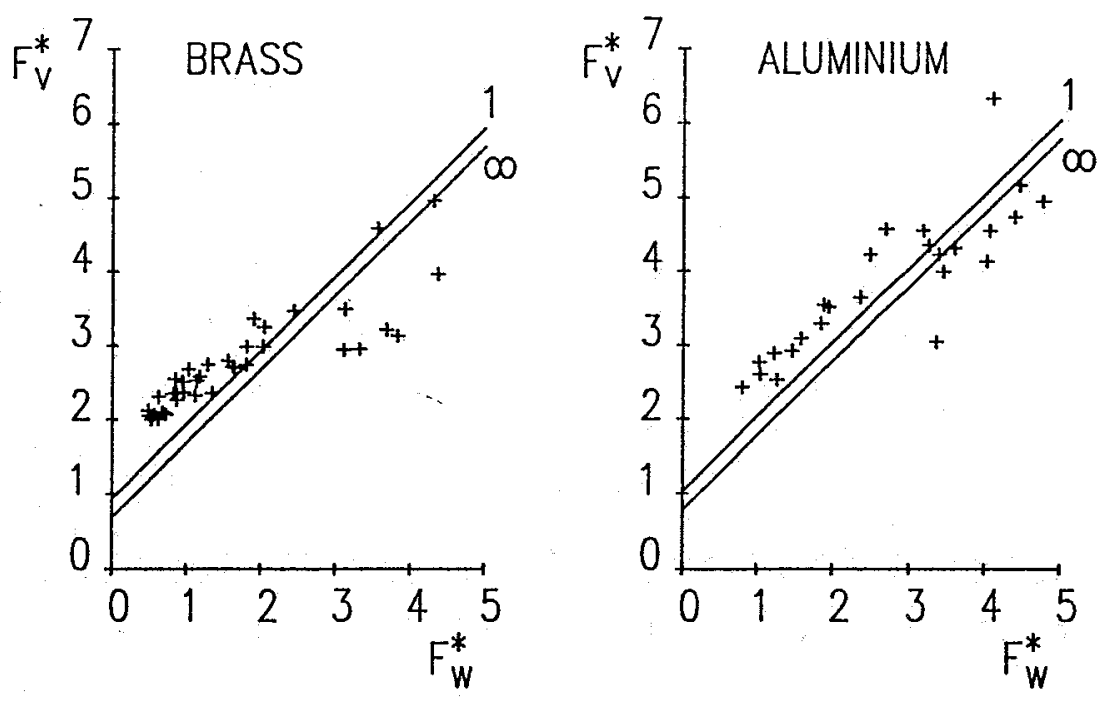

Fig.4. The cutting force number versus the friction force number without correction
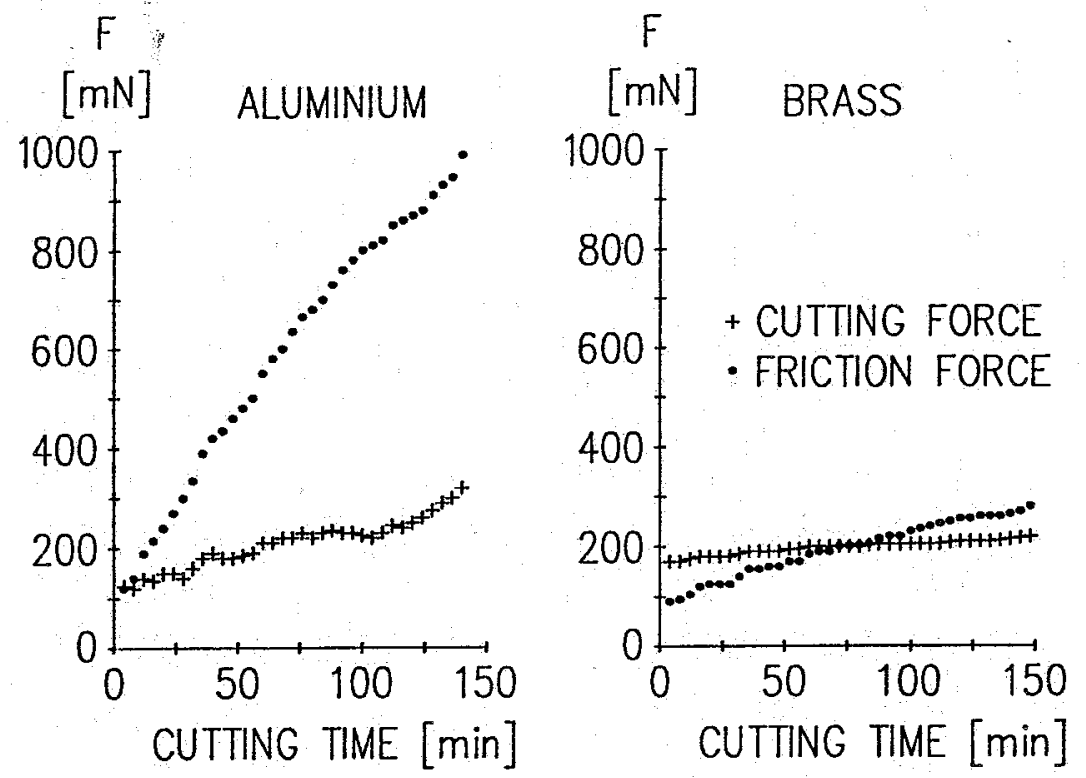

Fig.5. The cutting forces versus the cutting time 

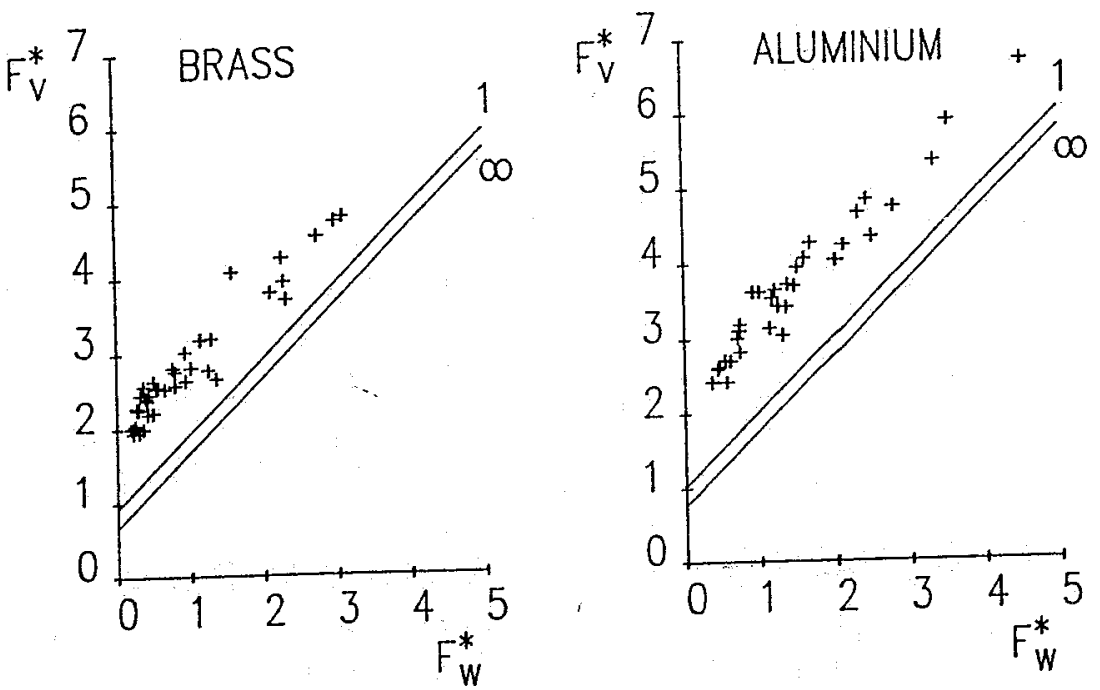

Fig.6. The cutting force number versus the friction force number corrected for tool wear
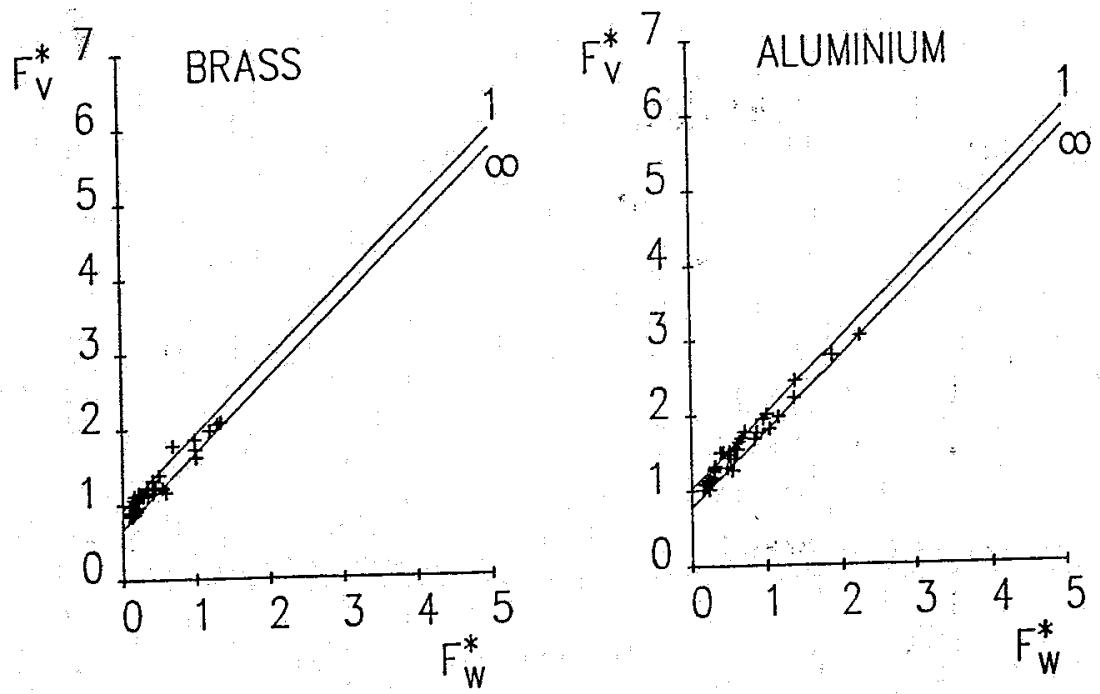

Fig.7. The cutting force number versus the friction force number corrected for tool wear and specific stresses 


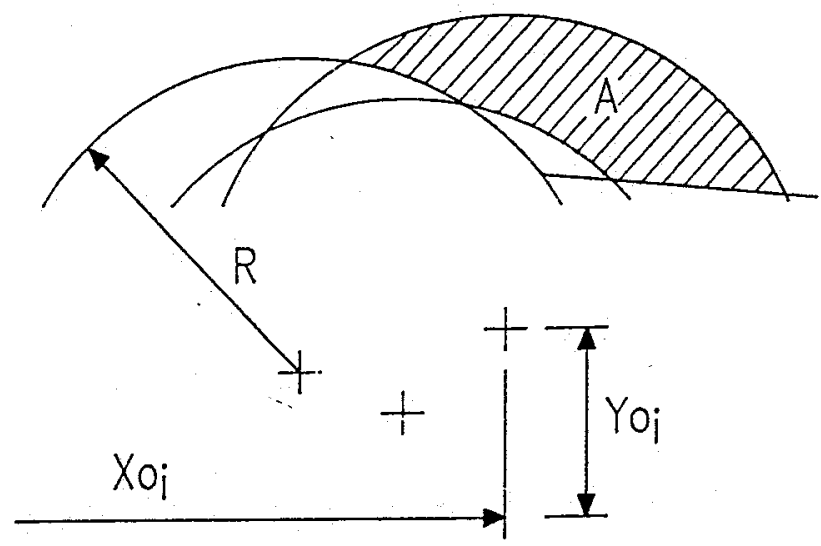

Fig.8. The position of the tool with respect to the work-piece and the undeformed chip section

Roughness

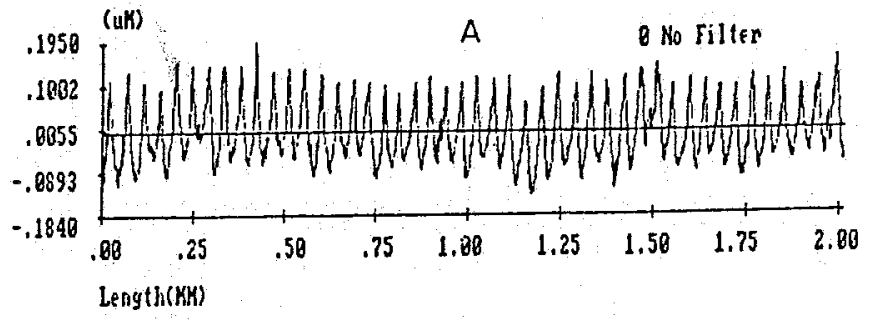

Roughness values

$[\mu \mathrm{m}]$

$R_{t}=0.329$

$R_{q}=0.071$

$R_{a}=0.060$

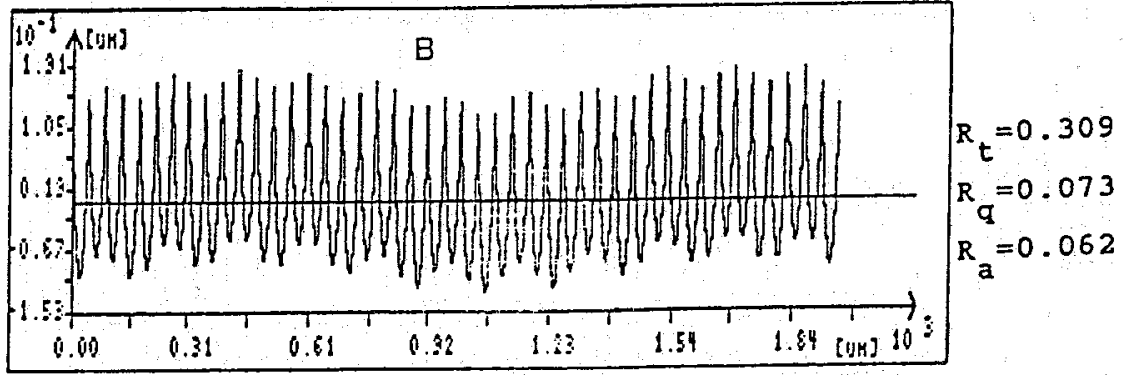

Fig.9. The measured (A) and estimated (B) profiles of a brass work-piece. Feed $=40 \mu \mathrm{m} / \mathrm{rev}$. 


\section{Roughness}

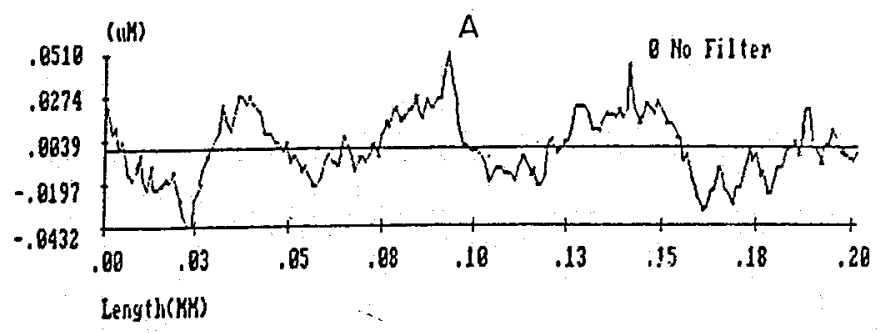

Roughness values [ $\mu \mathrm{m}]$

$$
R_{t}=0.086
$$$$
R_{q}=0.017
$$$$
R_{a}=0.014
$$

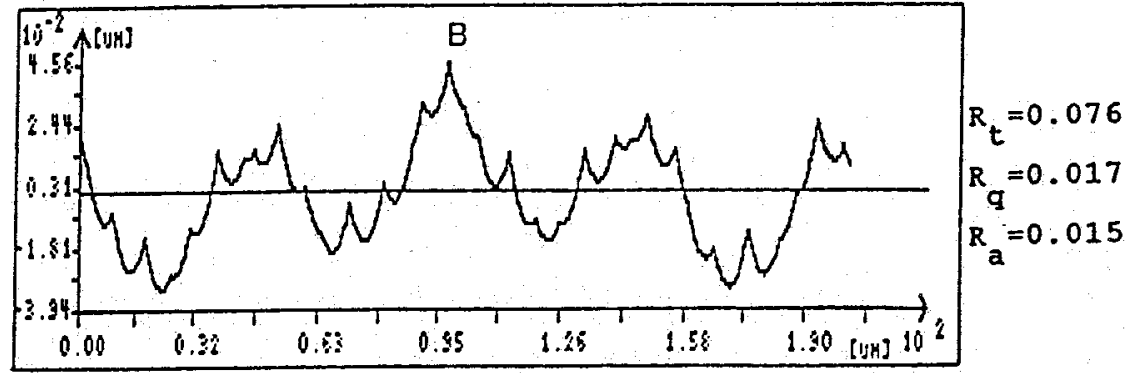

Fig.10. The measured (A) and estimated (B) profiles of a brass work-piece. Feed $=6 \mu \mathrm{m} / \mathrm{rev}$. 


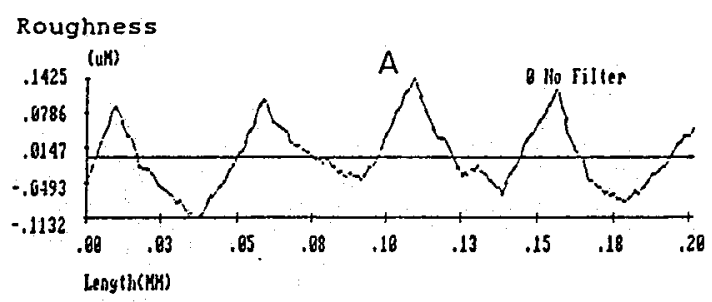

Roughness

values

$[\mu \mathrm{m}]$

$R_{t}=0.255$

$R_{\mathrm{q}}=0.058$

$R_{a}=0.047$

Roughness

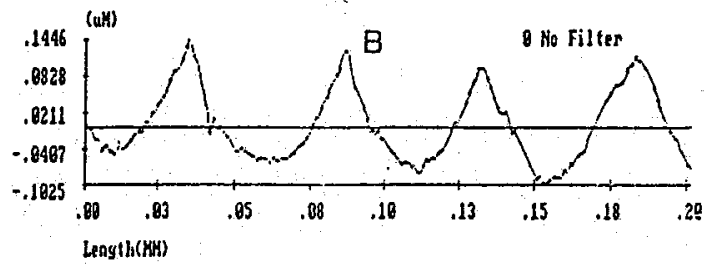

$R_{t}=0.230$

$R_{q}=0.059$

$R_{a}=0.051$

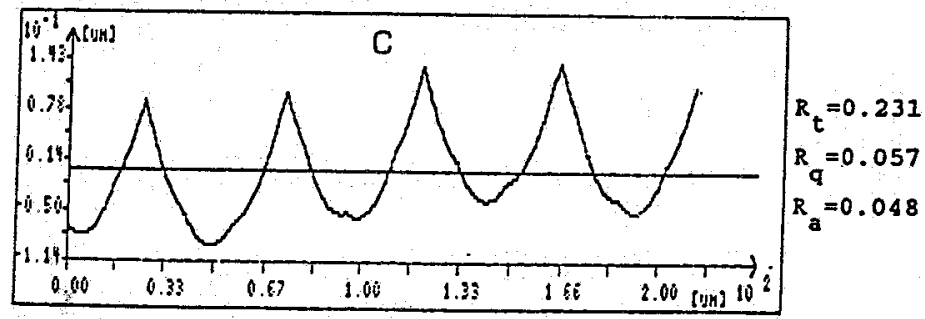

Fig.11. The measured profile of a brass (A) and an aluminium (B) work-piece and the estimated profile (C). Feed $=5 \mu \mathrm{m} / \mathrm{rev}$. 